\title{
Multifunctional polarization mapping system of networks of biological crystals in the diagnostics of pathological and necrotic changes of human organs
}

O. Ushenko, V. Zhytaryuk, V. Dvorjak, I. V. Martsenyak, O. Dubolazov, et al.

O. Ushenko, V. Zhytaryuk, V. Dvorjak, I. V. Martsenyak, O. Dubolazov, B. G. Bodnar, O. Ya. Vanchulyak, S. Foglinskiy, "Multifunctional polarization mapping system of networks of biological crystals in the diagnostics of pathological and necrotic changes of human organs," Proc. SPIE 11087, Biosensing and Nanomedicine XII, 110870 S (9 September 2019); doi: $10.1117 / 12.2529362$

EPIE Event: SPIE Nanoscience + Engineering, 2019, San Diego, California, United States 


\title{
Multifunctional polarization mapping system of networks of biological crystals in the diagnostics of pathological and necrotic changes of human organs
}

\author{
O.Ushenko $^{1}$, V.Zhytaryuk ${ }^{1}$, V. Dvorjak ${ }^{1}$, I.V. Martsenyak ${ }^{1}$, O.Dubolazov ${ }^{1}$ \\ B.G. Bodnar ${ }^{2}$, O.Ya. Vanchulyak ${ }^{2}$, S.Foglinskiy ${ }^{1}$ \\ ${ }^{1}$ Chernivtsi National University, 2 Kotsiubynskyi Str., Chernivtsi, Ukraine, 58012 \\ ${ }^{2}$ Bukovinian State Medical University, 3 Theatral Sq., Chernivtsi, Ukraine, 58000 \\ a.dubolazov@chnu.edu.ua
}

\begin{abstract}
The results of multifunctional polarization-phase mapping of histological sections of adenoma and prostate carcinoma are presented. Used methods of statistical and wavelet analysis. The criteria for differentiation of benign and malignant conditions are obtained.
\end{abstract}

Keywords: biological crystals, polarization-phase mapping, of benign and malignant conditions

\section{Introduction}

The processes of conversion of the parameters of laser electromagnetic radiation in the optical wavelength range with biological objects are considered in many approximations:

- photometry and spectrophotometry (light scattering optics) ${ }^{1,2}$;

- polarimetry (vector - parametric and matrix optics) ${ }^{3,4}$;

- Corelometry (correlation optics, fractal and singular optics) ${ }^{5-12}$.

In recent years, new approaches have emerged on the basis of these directions to the study of scattered radiation fields laser polarimetry of biological layers ${ }^{13-19}$.

Within this research direction, it was possible to determine the fundamental relationships between a set of statistical (moments of the 1st - 4th order), correlation (autocorrelation functions), fractal (fractal dimensions) and singular (a network of points with polarization singular states) characterizing the distribution of directions optical axes and birefringence values of histological sections of biological tissues and coordinate distributions of azimuths and ellipticity of polarization of their laser microscopic images ${ }^{15}$.

However, in the processes of laser radiation conversion by amorphous biological layers, polarization modulation is practically absent. However, the phase distributions of microscopic images of such objects remain informative.

Therefore, the further development of new approaches to the analysis of the phase structure of microscopic images of weakly anisotropic (amorphous) biological layers is relevant.

\section{Experimental research methods}

\subsection{Polarization phase metering system}

The optical scheme of the implementation of this method is shown in fig. $1^{14}$. 


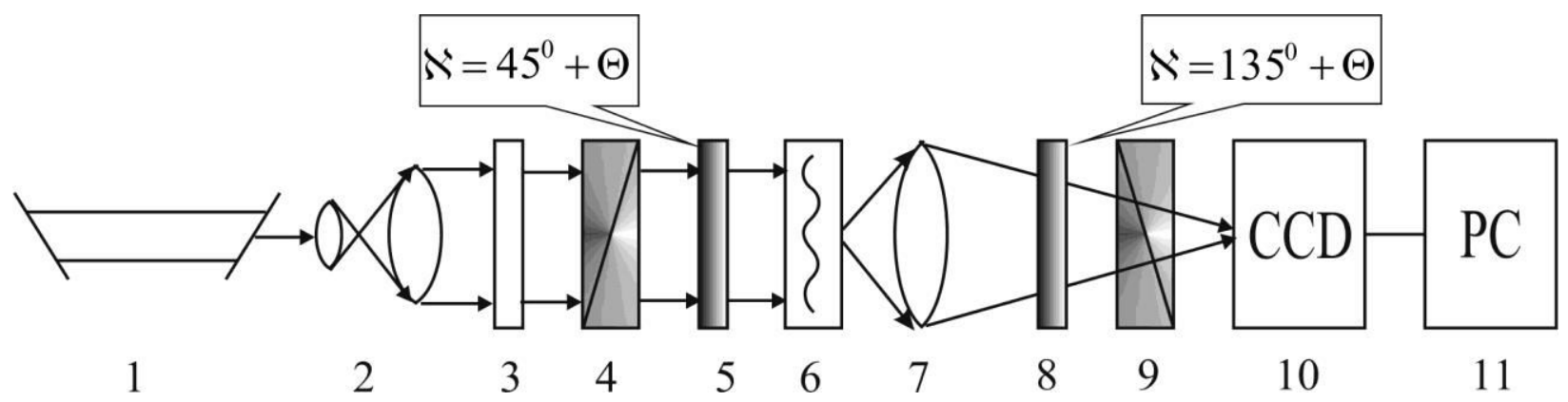

Fig. 1. Optical scheme of the polarimeter - phase meter, where 1 - He-Ne laser; 2 - collimator; $3,5,8$ - stationary quarter-wave plates; 4, 9 - polarizer and analyzer, respectively; 6 - the object of study; 7 - micro lens; 10 - CCD camera; 11 - personal computer.

For information on the phase-shifting ability of histological sections of biological tissues and polycrystalline films of biological fluids 6 transmission plane and the direction of the main optical axes of the main polarization elements polarizers 4 ; 9 and phase plates " $\lambda / 4$ " 3; 8 - oriented at angles $\aleph=45^{0}+\Theta$ and $\aleph=135^{0}+\Theta$.

Under such conditions, the intensity of each point of the polarization-filtered image of histological sections of biological tissues and polycrystalline films of biological fluids is determined by the ratio

$$
I=2 \sin ^{2} 0,5 \delta
$$

Here $I$ is the intensity of the digital microscopic image in each individual pixel of the digital camera; $\delta$ - phase shift, which is introduced by the substance of a biological preparation and characterizes the degree of its crystallization. Thus, the coordinate distribution of the phase shifts of the polycrystalline component of the histological section can be obtained.

Thus, it is possible to obtain the coordinate distribution of the phase shifts of the polycrystalline component of the histological section $\varphi(m \times n)$.

$$
\delta=\left(\begin{array}{ccc}
\delta_{11} & \ldots & \delta_{1 n} \\
& \delta_{j k} & \\
\delta_{m 1} & \ldots & \delta_{m n}
\end{array}\right)=\left(\begin{array}{ccc}
2 \arcsin \sqrt{0,5 I_{11}} & \ldots & 2 \arcsin \sqrt{0,5 I_{1 n}} \\
2 \arcsin \sqrt{0,5 I_{m 1}} & \ldots & 2 \arcsin \sqrt{I_{j k}} \\
\end{array}\right) .
$$

\subsection{Wavelet analysis of phase maps of microscopic images of histological sections of the bening (group 1) and malignant (group 2) samples}

The results of the wavelet analysis of phase maps of microscopic images of FB histological sections are shown in a series of fig. 2 - fig. 3. 

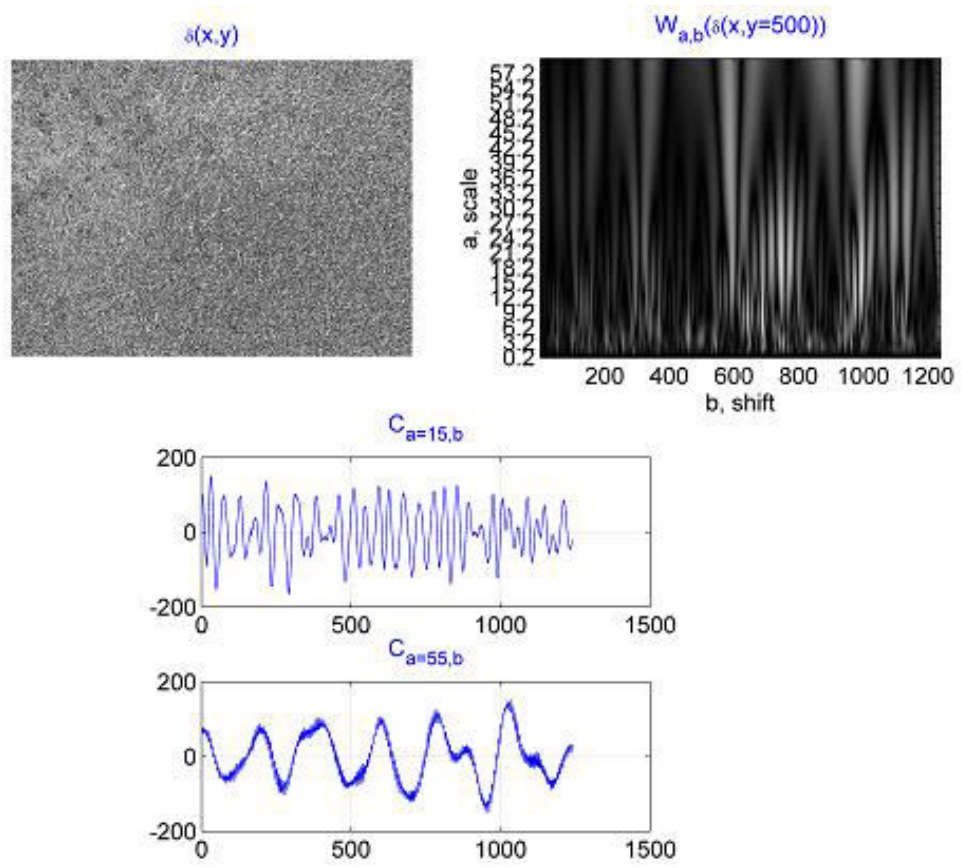

Fig. 2. Two-dimensional distributions of phases $\delta(x, y)$, wavelet coefficients $Q_{a, b}$ and their different-scale sections $C_{a=15, b}$ and $C_{a 55, b}$ for microscopic imaging of the histological section of biotissue from group 1
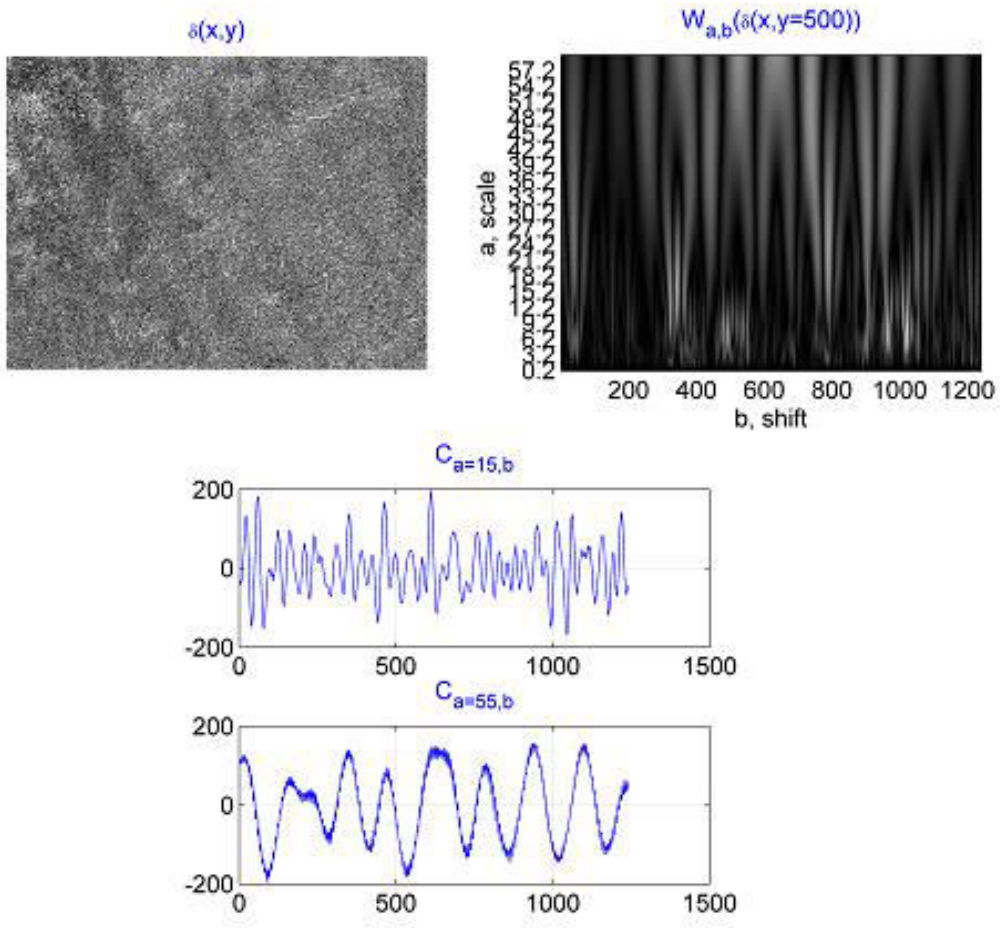

Fig. 3. Two-dimensional distributions of phases $\delta(x, y)$, wavelet coefficients $Q_{a, b}$ and their different-scale sections $C_{a=15, b}$ and $C_{a 55, b}$ for microscopic imaging of the histological section of biotissue from group 2 
A comparative analysis of the results of the study of the wavelet coefficient maps of the coordinate distributions of the phases of polarization-filtered microscopic images of histological sections of tissue (group 1) revealed distinct differences between them at the level of small scales $a_{\min }$ of the MHAT function. This fact is also indicated by the large modulation depth of the "small-scale" dependences $C_{a=15, b}$ characterizing the degree of crystallization.

This fact can be attributed to the fact that the morphological changes in this sample do not occur at a large scale, but at a small scale level. Due to this, the modulation depth of the amplitudes of the wavelet coefficients on small $a_{\min }$ scales of scanning of the wavelet function $\Omega_{a, b}$ of phase maps increases. Quantitatively, this is reflected in the growth of the dispersion $M_{i=2}\left(C_{a=15, b}(\Delta f)\right) \uparrow$ and the statistical moments of higher orders $M_{i=3 ; 4}\left(C_{a=15, b}(\Delta f)\right) \uparrow$ - table 1 .

Table 1 Statistical moments of the 1st - 4th orders characterizing the distributions $C_{a=15, b}$ and $C_{a 55, b}$ wavelet coefficients of the phase maps of microscopic images of histological sections of FB

\begin{tabular}{|c|c|c|c|}
\hline$a$ & Group 1 & Group 2 \\
\hline$a_{\text {min }}=15$ & & $0,05 \pm 0,009$ & $0,19 \pm 0,001$ \\
\cline { 2 - 4 } & & $0,08 \pm 0,052$ & $0,26 \pm 0,038$ \\
\cline { 2 - 4 } & & $0,21 \pm 0,041$ & $0,81 \pm 0,032$ \\
\cline { 2 - 4 }$a_{\max }=55$ & & $0,28 \pm 0,029$ & $0,97 \pm 0,13$ \\
\cline { 2 - 4 } & & $0,04 \pm 0,007$ & $0,07 \pm 0,006$ \\
\cline { 2 - 4 } & & $0,11 \pm 0,036$ & $0,22 \pm 0,031$ \\
\cline { 2 - 4 } & & $0,54 \pm 0,072$ & $0,31 \pm 0,018$ \\
\cline { 2 - 4 } & & $0,97 \pm 0,12$ & $0,59 \pm 0,11$ \\
\hline
\end{tabular}

\section{Conclusions}

The following quantitative criteria for statistically significant differentiation of bening (group 1) and malignant (group 2) samples were established.

$$
a_{\min } \Leftrightarrow\left\{\begin{array} { l } 
{ \Delta Z _ { 1 } ( S _ { 2 } ) = 5 , 2 5 ; } \\
{ \Delta Z _ { 2 } ( S _ { 2 } ) = 4 , 2 1 ; } \\
{ \Delta Z _ { 3 } ( S _ { 3 } ) = 5 , 9 ; } \\
{ \Delta Z _ { 4 } ( S _ { 4 } ) = 4 , 8 5 . }
\end{array} a _ { \operatorname { m a x } } \Leftrightarrow \left\{\begin{array}{l}
\Delta Z_{1}\left(S_{2}\right)=2,15 ; \\
\Delta Z_{2}\left(S_{2}\right)=2,2 ; \\
\Delta Z_{3}\left(S_{3}\right)=2,9 ; \\
\Delta Z_{4}\left(S_{4}\right)=2,8 .
\end{array}\right.\right.
$$

Thus, the method of wavelet analysis of the phase distribution of microscopic images of bening (group 1) and malignant (group 2) samples is $2-3$ times more sensitive than direct phasemetry ${ }^{13-19}$, which significantly expands the functionality of the time differentiation of such objects. 


\section{REFERENCES}

[1]. Wang X. Propagation of polarized light in birefringent turbid media: a Monte Carlo study / X. Wang, L.-H. Wang // J. Biomed. Opt. - 2002. - Vol. 7. - P. 279-290.

[2]. Tuchin V. V. Handbook of optical biomedical diagnostics / V. V. Tuchin. - Bellingham : SPIE Press, $2002 .-1110$ p.

[3]. Yao G. Two-dimensional depth-resolved Mueller matrix characterization of biological tissue by optical coherence tomography / G. Yao, L. V. Wang // Opt. Lett. - 1999. - V. 24. - P. 537-539.

[4]. Tower T. T. Alignment Maps of Tissues: I. Microscopic Elliptical Polarimetry / T. T. Tower, R. T. Tranquillo // Biophys. J. - 2001. - Vol. 81. - P. 2954-2963.

[5]. Lu S. Interpretation of Mueller matrices based on polar decomposition / S. Lu, R. A. Chipman // J. Opt. Soc. Am. A. 1996. - Vol. 13. - P.1106-1113.

[6]. Ghosh Nirmalya. Techniques for fast and sensitive measurements of two-dimensional birefringence distributions / Nirmalya Ghosh, I. Alex Vitkin // Journal of Biomedical Optics. - 2011. - № 16(11). - P. 110801.

[7]. V. V. Tuchin, L. Wang, and D. A`. Zimnyakov, Optical Polarization in Biomedical Applications, New York, USA (2006).

[8]. Angelsky, O.V., Ushenko, A.G., Ushenko, Y.A., Pishak, V.P. , "Statistical and fractal structure of biological tissue mueller matrix images," (2007) Optical Correlation Techniques and Applications, pp. 213-265.

[9]. Angelsky, O.V., Hanson, S.G., Maksimyak, P.P., Maksimyak, A.P., Zenkova, C.Yu., Polyanskii, P.V., Ivanskyi, D.I., "Influence of evanescent wave on birefringent microplates," (2017) Optics Express, 25 (3), pp. 2299-2311.

[10]. Angelsky, O., Yermolenko, S., Prydij, O., Ushenko, A., Ushenko, Yu. G., Ushenko, Ye., "Polarization-Interference Structure of Speckle Fields of the Rough Skin Surface," (2006), Journal of Holography and Speckle (3), 27-34.

[11]. Angelsky, O.V., Ushenko, Y.A., Dubolazov, A.V., Telenha, O.Yu., "The interconnection between the coordinate distribution of mueller-matrixes images characteristic values of biological liquid crystals net and the pathological changes of human tissues," (2010) Advances in Optical Technologies, 130659.

[12]. Angelsky, O.V., Bekshaev, A.Y.A., Maksimyak, P.P., Maksimyak, A.P., Hanson, S.G., "Low-temperature laserstimulated controllable generation of micro-bubbles in a water suspension of absorptive colloid particles," (2018) Optics Express, 26 (11), pp. 13995-14009.

[13]. Ushenko, Yu.A., Dubolazov, A.V., Karachevtcev, A.O., Zabolotna, N.I. A fractal and statistic analysis of Muellermatrix images of phase inhomogeneous layers (2011) Proceedings of SPIE - The International Society for Optical Engineering, 8134, 81340P.

[14]. Dubolazov, A.V., Pashkovskaya, N.V., Ushenko, Yu.A., Marchuk, Yu.F., Ushenko, V.A., Novakovskaya, O.Yu. Birefringence images of polycrystalline films of human urine in early diagnostics of kidney pathology (2016) Applied Optics, 55 (12), pp. B85-B90.

[15]. Dubolazov, A.V., Koval, G.D., Zabolotna, N.I., Pavlov, S.V. Fractal structure of optical anisotropy Mueller-matrices images of biological layers (2013) Proceedings of SPIE - The International Society for Optical Engineering, 9066, $90661 \mathrm{~W}$.

[16]. Ushenko, V.A., Sidor, M.I., Marchuk, Yu.F., Pashkovskaya, N.V., Andreichuk, D.R. Azimuth-invariant mueller-matrix differentiation of the optical anisotropy of biological tissues (2014) Optics and Spectroscopy (English translation of Optika i Spektroskopiya), 117 (1), pp. 152-157.

[17]. Ushenko, V.A., Pavlyukovich, N.D., Trifonyuk, L. Spatial-frequency azimuthally stable cartography of biological polycrystalline networks (2013) International Journal of Optics, 2013, 683174 .

[18]. Ushenko, V.A., Zabolotna, N.I., Pavlov, S.V., Burcovets, D.M., Novakovska, O.Yu. Mueller-matrices polarization selection of two-dimensional linear and circular birefringence images (2013) Proceedings of SPIE - The International Society for Optical Engineering, 9066, 90661X.

[19]. Ushenko, V.O. Two-dimensional mueller matrix phase tomography of self-similarity birefringence structure of biological tissues (2012) Proceedings of SPIE - The International Society for Optical Engineering, 8487, 84870W. 